\title{
Omega-3 Fatty Acids Reduce Lipopolysaccharide-Induced Abnormalities in Expression of Connexin-40 in Aorta of Hereditary Hypertriglyceridemic Rats
}

\author{
K. FRIMMEL ${ }^{1}$, R. SOTNÍKOVÁ ${ }^{2}$, J. NAVAROVÁ ${ }^{2}$, I. BERNÁTOVÁ ${ }^{3}$, J. KRIŽÁK ${ }^{1}$, \\ Z. HAVIAROVÁ ${ }^{4}$, B. KURA ${ }^{1}$, J. SLEZÁK ${ }^{1}$, L. OKRUHLICOVÁ ${ }^{1}$ \\ ${ }^{1}$ Institute for Heart Research, Slovak Academy of Sciences, Bratislava, Slovak Republic, ${ }^{2}$ Institute \\ of Experimental Pharmacology and Toxicology, Slovak Academy of Sciences, Bratislava, Slovak \\ Republic, ${ }^{3}$ Institute of Normal and Pathological Physiology, Slovak Academy of Sciences, \\ Bratislava, Slovak Republic, ${ }^{4}$ Faculty of Medicine, Comenius University, Bratislava, Slovak \\ Republic
}

Received June 10, 2016

Accepted June 24, 2016

\begin{abstract}
Summary
Omega-3 fatty acids ( $\Omega 3 F A$ ) are known to reduce hypertriglyceridemia- and inflammation-induced vascular wall diseases. However, mechanisms of their effects are not completely clear. We examined, whether 10-day $\Omega 3 F A$ diet can reduce bacterial lipopolysaccharide-induced changes in expression of gap junction protein connexin40 (Cx40) in the aorta of hereditary hypertriglyceridemic (hHTG) rats. After administration of a single dose of lipopolysaccharide (LPS, $1 \mathrm{mg} / \mathrm{kg}$, i.p.) to adult hHTG rats, animals were fed with $\Omega 3 F A$ diet (30 mg/kg/day) for 10 days. LPS decreased Cx40 expression that was associated with reduced acetylcholine-induced relaxation of aorta. $\Omega 3 F A$ administration to LPS rats had partial anti-inflammatory effects, associated with increased Cx40 expression and improved endothelium dependent relaxation of the aorta. Our results suggest that 10-day $\Omega 3 F A$ diet could protect endothelium-dependent relaxation of the aorta of hHTG rats against LPS-induced damage through the modulation of endothelial Cx40 expression.
\end{abstract}

\section{Key words}

Lipopolysaccharide - Omega-3 fatty acids - Connexin-40 • Hypertriglyceridemia • Rat aorta

\section{Corresponding author}

K. Frimmel, Institute for Heart Research, Slovak Academy of Sciences, Dúbravská cesta 9, P.O.Box 104, Bratislava 840 05, Slovak Republic. E-mail: usrdfrim@savba.sk

\section{Introduction}

Vascular intercellular gap junctions are transmembrane channels allowing passage of ions and small metabolites and molecules $(<1 \mathrm{kDa})$ directly between two adjacent cells synchronizing cell functions along vascular wall (Figueroa and Duling 2009). Gap junctions are formed by two hemichannels (connexons). Each connexon consists from six connexin proteins $(\mathrm{Cx})$ and can exist in an unpaired state as well (Perkins et al. 1998). Vascular cells express four types of Cx isoforms (of the 21-member family of Cxs) (Söhl and Willecke 2004). Their expression is dependent on the type of blood vessels and cells as well as animal species (Van Kempen and Jongsma 1999). Pathophysiological conditions-induced disturbances in expression of $\mathrm{Cx}$ isoforms reported in many studies (Burnier et al. 2009, Dlugošová et al. 2009a,b, Laird 2010) underline participation of gap junctions in a development of vascular wall injury and their potential role in treatment of vascular disorders. $\mathrm{Cx} 40$ is a major connexin expressed in endothelial cells (Brisset et al. 2009). Abnormalities in its expression observed during hypertriglyceridemia (Okruhlicová et al. 2012) as well as during atherosclerotic plaque development (Kwak et al. 2002) signify the role of $\mathrm{Cx} 40$-channels in a development of endothelial dysfunction which is generally accepted as a key step in development of vascular wall damage (Okumura et al. 2005). 
Atherosclerosis is recognized as a multifactorial vascular disease, associated with the inflammation during all its phases. It was reported that Gram-negative bacteria might represent one of the risk factors involved in the initiation and/or progression of atherosclerosis (Al-Banawi et al. 2011, Libby and Simon 2001). The response of body to bacteria or bacterial lipopolysaccharide (LPS) is known to be associated with overproduction of various inflammatory mediators and oxidative stress which cause endothelial dysfunction (Guzik et al. 2003, Sprague and Khalil 2009). There are numerous studies, including ours, which demonstrate that LPS and/or inflammatory mediators influenced expression of $\mathrm{Cx}$ isoforms and GJ function in vascular wall (Rignault et al. 2005, 2007, Frimmel et al. 2014) and circulating leukocytes, as well (Oviedo-Orta et al. 2002, Wong et al. 2004). All data emphasize the participation of $\mathrm{Cx}$-channels in modulation of vascular wall response during inflammation. Moreover, it was reported that LPS administration can increase plasma levels of triglycerides (TG) and TG-rich lipoproteins (Uchiumi et al. 2004). Hypertriglyceridemia (HTG) represents an independent risk factor for atherosclerosis, therefore LPS-induced elevation of TG can represent additional risk for atherosclerosis in subjects with inherited and/or acquired dyslipidemia (Feingold et al. 1992).

Hereditary HTG (hHTG) rats were selectively bred as an experimental model for study of mechanisms of human HTG (Vrana and Kazdova 1990). In this model, elevated levels of TG are associated with a moderate hypertension, metabolic disorder of glucose and cholesterol as well as impaired function and structure of cardiovascular system (Zicha et al. 2006). The hHTG-related abnormalities in expression of $\mathrm{Cx} 40$ and Cx43 isoforms found in the rat aorta and the myocardium (Dlugošová et al. 2009b, Bacova et al. 2010, Radosinska et al. 2011, Okruhlicova et al. 2012) indicate the involvement of $\mathrm{Cx}$-channels in the above mentioned disturbances of cardiovascular system of hHTG subjects. However, according to our knowledge, the effects of LPS on $\mathrm{Cx}$ expression in a vascular system of HTG subjects have not been studied yet.

Beneficial effects of TG lowering in reduction of atherosclerosis and cardiovascular diseases have been observed in numerous clinical trials. Lifestyle influences, including omega-3 fatty acids ( $\Omega 3 \mathrm{FA}$ ) rich diet, play primary strategies in effective reduction in the incidence of cardiovascular diseases. $\Omega 3 F$ F are well-known for their multiple protective effects, e.g. reducing of plasma lipid levels, inflammation and oxidative stress, improving of NO production, endothelial function (Calder 2012) and renal $\mathrm{Na} / \mathrm{K}$-ATPase activity (Mézešová et al. 2013) as well as modulating of physical structure of cellular membranes and their ion currents (Pirillo and Catapano 2013). Our previous studies showed that chronic $\Omega 3 F A$ supplementation caused modulation of $\mathrm{Cx} 43$ expression in the aorta and myocardium of hHTG rats (Dlugošová et al. 2009b, Bacova et al. 2010, Radosinska et al. 2011). Our recent work showed that also short-term $\Omega 3$ FA diet can affect LPS-induced disturbances of $\mathrm{Cx} 40$ expression in the aorta of rats (Frimmel et al. 2014). The results together indicate the involvement of $\mathrm{CX}$-channels in cardioprotective mechanisms of $\Omega 3 \mathrm{FA}$. However, it has not been studied yet if short-term $\Omega 3 F$ A supplementation of hHTG rats can protect $\mathrm{Cx} 40$ expression in a vascular system after LPS challenge. Therefore, the aim of the present study was to examine the influence of LPS and $\Omega 3 F A$ on the expression and distribution of $\mathrm{Cx} 40$ in the aorta of hHTG rats.

\section{Materials and Methods}

\section{Animal model}

The experiments were performed in accordance with the rules issued by the State Veterinary Administration of the Slovak Republic, Act No. 377/2012 Coll. and with the rules of the Animal Research and Care Committee of Institute for Heart Research SAS. The animals were anesthetized with thiopental $(50 \mathrm{mg} / \mathrm{kg}$, i.p.) and the aorta was excised for functional, biochemical and microscopic studies.

In 10-day lasting experiment, 3-month-old hHTG male rats $(270-300 \mathrm{~g})$ were used. They were divided into four groups ( $n=6)$ : 1) the control group (C) - rats fed a standard diet, 2) the $\Omega 3$ group - rats fed a standard diet enriched with $\Omega 3 F A$ (30 $\mathrm{mg} / \mathrm{kg} / \mathrm{day}), 3$ ) the L group - rats injected with a single dose of LPS (1 mg/kg, i.p.) and 4) the $L \Omega 3$ group - the $L$ rats fed a diet enriched with $\Omega 3 F A$. LPS (Escherichia coli serotype 055:B5, Sigma Chemical, Germany) was dissolved in sterile $0.9 \% \mathrm{NaCl}$ solution. The rats from the groups 1) and 2) were injected with the same volume of sterile $0.9 \% \mathrm{NaCl}$ solution. $\Omega 3 \mathrm{FA}$ consisted of $57 \%$ eicosapentaenoic acid and $43 \%$ docosahexaenoic acid (commercial nutritional supplement of MaxiCor, SVUS Pharma, Czech Republic).

\section{Measurement of physiological and biochemical parameters}

Body weight and systolic blood pressure were 
measured at the beginning and at the end of the experiment. Blood pressure was measured by non-invasive method of tail-cuff plethysmography using the device ML866/P PowerLab4/30 (AD Instruments GmBH, Germany). To reduce the influence of stress on blood pressure, the animals were handled and acclimatized according to Dlugosova et al. (2009a). Each measurement was repeated five to six times in one rat.

At the end of the experiment, blood samples were collected for plasma separation which was stored at $-82{ }^{\circ} \mathrm{C}$ until the further analyses. Plasma levels of high sensitive C-reactive protein (CRP, marker of acute inflammation), TG and high-density lipoproteins (HDL) were measured using commercial clinical Cholestech LDX system (Cholestech Corporation, California, USA). The lactate dehydrogenase activity (LDH, marker of cellular and organ damage, cytotoxicity and hemolysis (Peppes et al. 2008) as well as acute inflammation) was measured in plasma using Randox kit (Laboratories Ltd., UK). The specific activity of lysosomal N-acetyl- $\beta$-D-glucosaminidase (NAGA, marker of lysosomal cellular damage and chronic phase of inflammation) (Krammer et al. 2006) was assayed in plasma according to standard method as described previously in Navarova and Nosalova (1994). The concentration of malondialdehyde (MDA, marker of lipid peroxidation) (Draper and Hadley 1989) was measured in liver, too.

Thoracic aorta was quickly excised and washed in a chilled saline, carefully cleaned from connective tissue and fat and used for the relaxation response study. Further part of the aortic tissue was stored at $-82{ }^{\circ} \mathrm{C}$ for immunofluorescent (IF) and Western blotting (WB) analyses and the nitric oxide synthase (NOS) activity measurement.

\section{NO synthase activity and functional responses of the aorta}

The activity of NOS was assayed in a homogenate of the aortic tissue by determination of $[3 \mathrm{H}]-\mathrm{L}$-citruline formation from [3H]-L-arginine (MP, Biomedicals) as described previously in Bernatova et al. (2002). We studied also functional relaxation of the aorta according to Sotnikova et al. (2006).

\section{Immunofluorescent detection of Cx40}

Indirect in situ immunodetection of $\mathrm{Cx} 40$ was performed on frozen cross-sections of the non-fixed aortic rings of the rats of all experimental groups according to Frimmel et al. (2014) with a minor modification concerning antibodies concentration. Shortly, fixed cryostat tissue sections of the aorta were incubated in the primary rabbit anti-Cx40 (Santa-Cruz, USA, 1:300) and the secondary anti-rabbit antibody (Johnson ImmunoResearch, USA, 1:300) labeled with fluorescein isothiocyanate (FITC). Immunofluorescent signal of $\mathrm{Cx} 40$ was monitored by confocal microscope Olympus FV1000. Obtained images were evaluated by morphometric analysis (Image J, Olympus). The total area of IF reaction per unit area of the aorta, together with the density of $\mathrm{Cx} 40$ spots and their average area were analyzed for demonstration of the spatial expression of $\mathrm{Cx} 40$. Seven sections per the rat aorta and eleven fields per the section were visualized and analyzed.

\section{Western blot analysis of Cx40 and CD68}

The frozen aortic tissue for Western blot was homogenized in SB20 (1 mg of tissue/10 ml of SB20 solution) and sonicated with a device UP $100 \mathrm{H}$ (Hielsher, Germany). The samples were diluted to the desired concentration by electrophoresis sample buffer and run on $10 \%$ polyacrylamide gel. After electrophoresis, the proteins were transferred to a nitrocellulose membrane. It was incubated in the blocking buffer consisting of $5 \%$ milk for $30 \mathrm{~min}$ and incubated in the rabbit monoclonal primary antibodies anti-Cx40 and anti-CD68 (marker of macrophage receptors) both at dilution 1:1000, followed by the incubation in peroxidase labeled with secondary polyclonal anti-rabbit antibody at a dilution 1:2000. The detection was performed using luminol system (chromophore), coumaric acid in a ratio of $3: 1$. Obtained chemiluminescent reaction was recorded by the device "KODAK in vivo FX" and evaluated by "Carestream SE". The result was given as the sum of grayscale intensity of each protein band and was normalized to GAPDH as an endogenous control.

\section{Results}

\section{Physiological and biochemical parameters}

Our results showed that LPS significantly reduced body weight gain of hHTG rats when compared with the C group (Table 1). 10-day $\Omega 3 F A$ supplementation had no apparent influence on the body weight gain in the $\Omega 3$ group. There was observed only a tendency towards a decreased weight gain. $\Omega 3$ FA diet had no significant effect on body weight gain in the L $\Omega 3$ group compared to the L one. No significant changes were observed in relative heart weight, systolic blood pressure and heart rate among the experimental groups (Table 1). 
Table 1. The effect of LPS and $\Omega 3 F A$ on selected biometric parameters.

\begin{tabular}{lcccc}
\hline & $\mathbf{C}$ & $\mathbf{\Omega 3}$ & $\mathbf{L}$ & $\mathbf{L} \mathbf{\Omega 3}$ \\
\hline$B W G(g)$ & $21 \pm 9$ & $14 \pm 4$ & $6 \pm 3^{*}$ & $4 \pm 4$ \\
$H W(g)$ & $1.01 \pm 0.01$ & $0.99 \pm 0.02$ & $1.002 \pm 0.047$ & $0.94 \pm 0.01$ \\
$H W / B W$ & $3.3 \pm 0.2$ & $3.7 \pm 0.4$ & $3.5 \pm 0.2$ & $3.3 \pm 0.2$ \\
$S B P \alpha(\mathrm{mm} \mathrm{Hg})$ & $114.0 \pm 12.4$ & $117.5 \pm 3.9$ & $124.5 \pm 9.9$ & $110.7 \pm 6.7$ \\
$S B P \omega(\mathrm{mm} \mathrm{Hg})$ & $121.0 \pm 4.6$ & $112.7 \pm 4.5$ & $116.8 \pm 6.1$ & $103.1 \pm 3.0$ \\
$H R \omega($ bpm) & $305 \pm 30$ & $291 \pm 32$ & $332 \pm 14$ & $286 \pm 21$ \\
\hline
\end{tabular}

Results are expressed as mean $\pm \mathrm{SEM}, \mathrm{n}=6$ animals per group, $* \mathrm{p}<0.05$ vs. C. BWG - body weight gain, HW - heart weight, HW/BW relative heart weight, $\mathrm{SBPa} / \mathrm{SBP} \omega$ - systolic blood pressure at the start/the end of the experiment, $\mathrm{HR} \omega$ - heart rate at the end of experiment.

Table 2. The effects of LPS and $\Omega 3 F A$ on selected biomarkers measured in plasma.

\begin{tabular}{lcccc}
\hline & $\mathbf{C}$ & $\mathbf{\Omega 3}$ & $\mathbf{L}$ & $\mathbf{L} \mathbf{\Omega 3}$ \\
\hline TG (mmol/l) & $1.65 \pm 0.12$ & $2.17 \pm 0.1^{*}$ & $2.01 \pm 0.11^{*}$ & $1.84 \pm 0.11$ \\
HDL (mmol/l) & $0.73 \pm 0.05$ & $0.66 \pm 0.04$ & $0.77 \pm 0.05$ & $0.76 \pm 0.05$ \\
Glu $(\mathrm{mmol} / \mathrm{l})$ & $11.5 \pm 0.2$ & $11.1 \pm 0.3$ & $10.8 \pm 0.2$ & $10.6 \pm 0.2$ \\
NAGA $(\mu \mathrm{g} / \mathrm{min} / \mathrm{mg}$ protein) & $0.059 \pm 0.004$ & $0.061 \pm 0.005$ & $0.087 \pm 0.008^{*}$ & $0.088 \pm 0.006^{*}$ \\
LDH $(\mathrm{U} / \mathrm{l})$ & $787 \pm 61$ & $1010 \pm 230$ & $1188 \pm 148^{*}$ & $943 \pm 117$ \\
CRP (mmol/l) & $<0.30$ & $<0.30$ & $<0.30$ & $<0.30$ \\
\hline
\end{tabular}

Results are expressed as mean $\pm \mathrm{SEM}, \mathrm{n}=6$ animals per group, $* \mathrm{p}<0.05$ vs. C. TG - triglycerides, HDL - high density lipoprotein, Glu glucose, NAGA - N-acetyl- $\beta$-D-glucosaminidase, LDH - lactate dehydrogenase, CRP - C-reactive protein.

Table 3. The effects of LPS and $\Omega 3 F A$ on the activity of $N$-acetyl- $\beta$-D-glucosaminidase (NAGA) and malondialdehyde (MDA) in liver.

\begin{tabular}{|c|c|c|c|c|}
\hline & $\mathbf{C}$ & $\mathbf{\Omega 3}$ & $\mathbf{L}$ & $\mathbf{L} \mathbf{\Omega 3}$ \\
\hline$N A G A(\mu \mathrm{g} / \mathrm{min} / \mathrm{mg}$ protein $)$ & $12.03 \pm 0.25$ & $12.27 \pm 0.62$ & $14.04 \pm 0.52 *$ & $12.76 \pm 0.19 * *$ \\
\hline$M D A(\mu g / m g$ protein $)$ & $1.33 \pm 0.039$ & $1.57 \pm 0.183$ & $2.24 \pm 0.371 *$ & $1.52 \pm 0.198^{\#}$ \\
\hline
\end{tabular}

Results are expressed as mean $\pm \mathrm{SEM}, \mathrm{n}=6$ animals per group, $* \mathrm{p}<0.05$ vs. $\mathrm{C}, \# \mathrm{p}<0.05$ vs. L.

LPS significantly increased TG plasma levels in the L group. Surprisingly, TG concentration in $\Omega 3$ group was also higher than in the controls (Table 2). $\Omega 3 F A$ treatment in the L $\Omega 3$ group did not markedly affect TG levels when compared to the $\mathrm{L}$ group, but there was a trend towards a decrease. No changes in HDL and glucose levels were observed among experimental groups after LPS and S3FA administration. On the other hand, the specific activity of NAGA was higher in the L group than in the $C$ group. $\Omega 3$ FA supplementation of the $L \Omega 3$ rats did not change the enzyme activity when compared to the L group. No significant differences in the activity of NAGA were observed between $\Omega 3$ and $C$ groups. LPS resulted in a significant elevation of the LDH activity. No differences in the enzyme activity were demonstrated between the $\mathrm{L}$ and $\mathrm{L} \Omega 3$ groups. There was seen a tendency towards a decline in the $L \Omega 3$ one. The measurement of the CRP concentration revealed no differences among the experimental groups (Table 2). In liver, LPS caused increase of the MDA concentration when compared to the $\mathrm{C}$ group. $\Omega 3 F$ A diet suppressed the MDA levels in the rats of the L $\Omega 3$ group (Table 3 ). $\Omega 3 F A$ supplementation did not affect MDA in $\Omega 3$ group. LPS resulted in marked increase of the NAGA specific activity in liver (Table 3 ). $\Omega 3$ FA diet reduced the enzyme activity in the L $\Omega 3$ group. $\Omega 3 F A$ had no effect on the enzymes activity compared to the $\mathrm{C}$ group. 


\section{NO synthase activity and vascular response of the aorta}

LPS caused the significant increase of the NOS activity when compared to the $\mathrm{C}$ group (Fig. 1). 10-day $\Omega 3 F A$ supplementation of the $L \Omega 3$ rats resulted in the additional elevation of the enzyme activity when compared to the $\mathrm{L}$ and the $\mathrm{C}$ groups. No differences in the NOS activity were found between the $\Omega 3$ group and the $\mathrm{C}$ group.

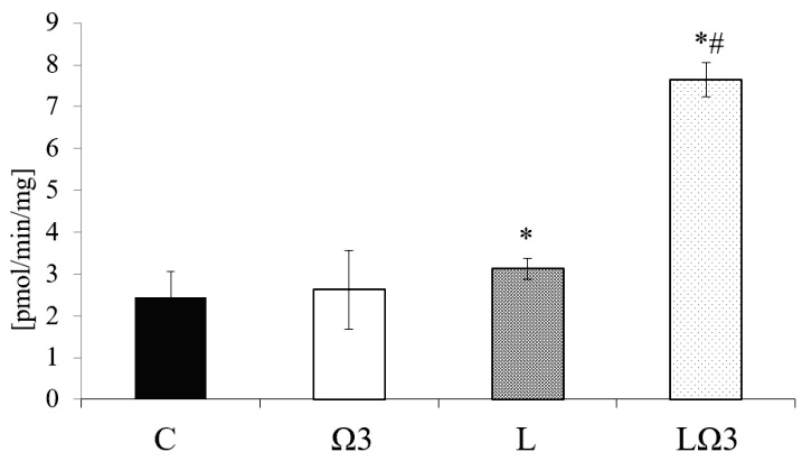

Fig. 1. The NO-synthase activity in the rat aorta. Results are mean \pm SEM, $n=6$ animals per group, $* p<0.05$ vs. $C, \# p<0.05$ vs. L. C - control hHTG rats, $\Omega 3-$ hHTG rats treated with $\Omega 3 F A$, $\mathrm{L}-\mathrm{hHTG}$ rats injected with LPS, L $\Omega 3$ - hHTG rats injected with LPS treated with $\Omega 3 F A$.

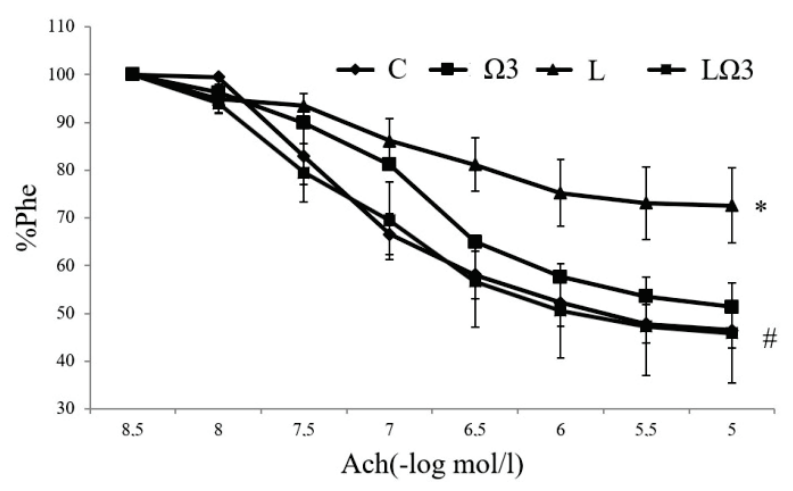

Fig. 2. The effect of LPS and $\Omega 3 F A$ on the endotheliumdependent relaxation of the aorta. C - control hHTG rats, $\Omega 3$ - hHTG rats treated with $\Omega 3 F A, L-$ hHTG rats injected with LPS, L $\Omega 3$ - hHTG rats injected with LPS treated with $\Omega 3 F A$, Phe - phenylephrine. * $\mathrm{p}<0.05$ vs. $\mathrm{C}, \# \mathrm{p}<0.05$ vs. L.

LPS administration resulted in the significant impairment of endothelium-dependent relaxation of the aorta compared to the $\mathrm{C}$ group (Fig. 2). In contrary, NPS-induced relaxation was not changed (Fig. 3). $\Omega 3 F A$ diet administered to the $\mathrm{L}$ rats caused the evident restoration of the ACh-induced modulation of aortic relaxation to the control level. $\Omega 3 \mathrm{FA}$ had no significant effect on the aortic relaxation response when compared to the $\mathrm{C}$ group.

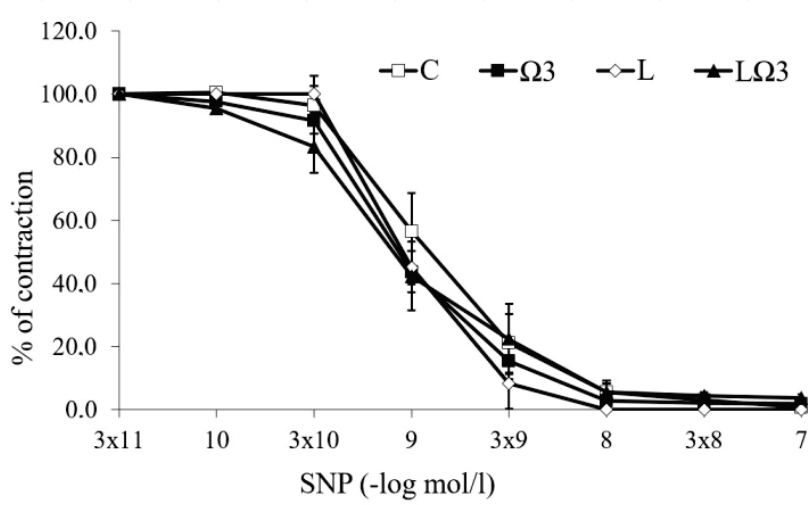

Fig. 3. The effect of LPS and $\Omega 3 F A$ on the endotheliumindependent relaxation of the aorta. C - control hHTG rats, $\Omega 3$ - hHTG rats treated with $\Omega 3 F A, L-h H T G$ rats injected with LPS, L $\Omega 3$ - hHTG rats injected with LPS treated with $\Omega 3 F A$, SNP - sodium nitroprusside.
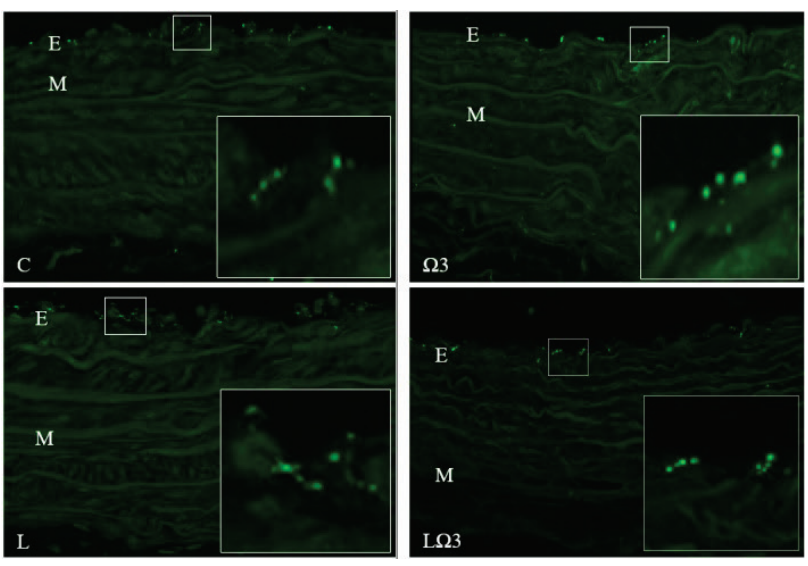

Fig. 4. Representative figures of $\mathrm{Cx} 40$ immunolabeling in endothelium (E) of the aorta of the control group (C), the inflammatory group (L), the control group treated with $\Omega 3 F A$ $(\Omega 3)$ and the treated inflammatory group $(L \Omega 3), M-$ media. $n=6$ animals per group. Original magnification: $x 40$.

\section{Immunofluorescent detection of $\mathrm{Cx} 40$}

Immunofluorescence (IF) revealed the distribution of $\mathrm{Cx} 40$ in endothelium of the aorta of all rats (Fig. 4). The morphometric analysis demonstrated that LPS reduced both the density (Fig. 5) and the total IF area of Cx40 (Fig. 6) when compared to the C group. $\Omega 3 F A$ supplementation of the rats injected with LPS increased the spots density and the total IF reaction compared to the $\mathrm{L}$ group. However, the values were still lower than in the $\mathrm{C}$ group. $\Omega 3 \mathrm{FA}$ diet did not markedly reduce the density of $\mathrm{Cx} 40$ spots, but it significantly suppressed the total IF reaction of $\mathrm{Cx} 40$ in the $\Omega 3$ group. No differences were observed among the experimental groups concerning the average size of $\mathrm{Cx} 40$ spots (Table 4). 


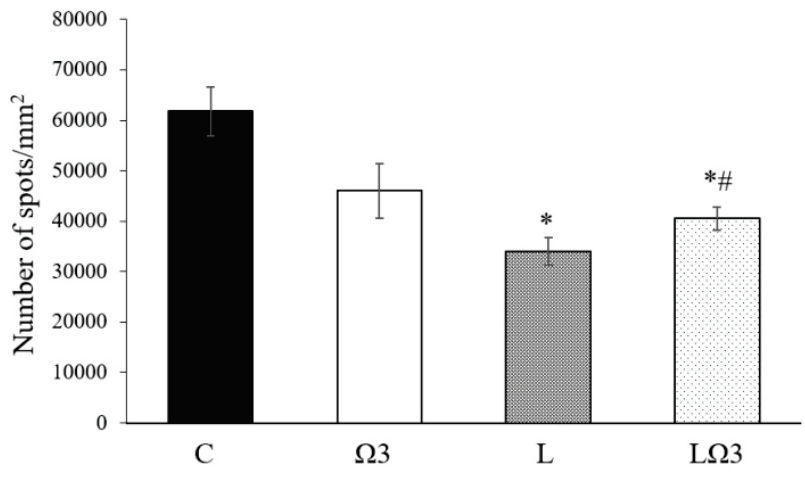

Fig. 5. Morphometric analysis of density of $\mathrm{Cx} 40$ spots in endothelium of the aorta control rats $(C)$, treated control rats $(\Omega 3)$, inflammatory rats $(L)$ and treated inflammatory rats $(L \Omega 3)$. Results are expressed as mean $\pm \mathrm{SEM}, \mathrm{n}=6$ animals per group, $* \mathrm{p}<0.05$ vs. $\mathrm{C}, \# \mathrm{p}<0.05$ vs. L.

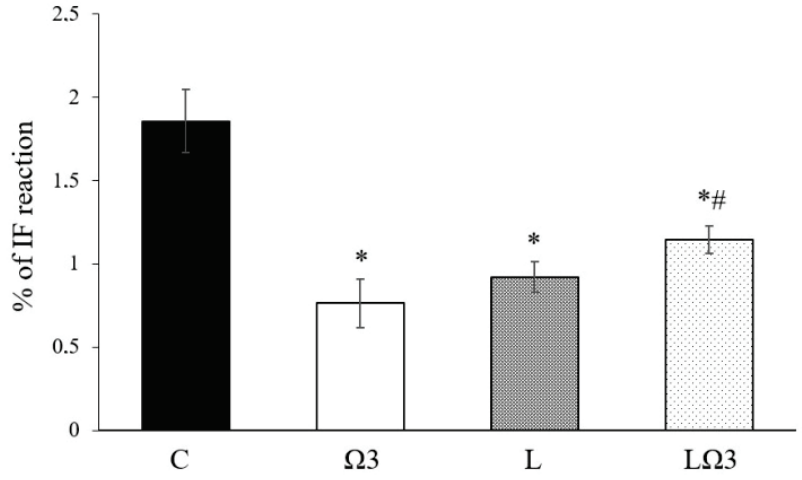

Fig. 6. Morphometric analysis of total immunofluorescent area of CX40 spots in endothelium of the aorta of experimental rats. Control rats $(C)$, treated control rats $(\Omega 3)$, inflammatory rats $(L)$ and treated inflammatory rats $(L \Omega 3)$. Results are expressed as mean \pm SEM, $n=6$ animals per group, $* p<0.05$ vs. C. $\# p<0.05$ vs. L, $\Omega 3$.

Table 4. Average size of single $\mathrm{C} x 40$ spot in the endothelium of the rat aorta of controls (C), treated controls ( $\Omega 3$ ), inflammatory group $(\mathrm{L})$ and treated inflammatory group $(\mathrm{L} \Omega 3)$.

\begin{tabular}{ccccc}
\hline & $\mathbf{C}$ & $\mathbf{\Omega 3}$ & $\mathbf{L}$ & $\mathbf{L} \mathbf{\Omega 3}$ \\
\hline Average size of spots $\left(\mu \mathrm{m}^{2}\right)$ & $0.291 \pm 0.009$ & $0.273 \pm 0.014$ & $0.262 \pm 0.008$ & $0.274 \pm 0.007$ \\
\hline
\end{tabular}

$\mathrm{n}=6$ animals per group.

A $\mathrm{Cx} 40$ GAPDH

B

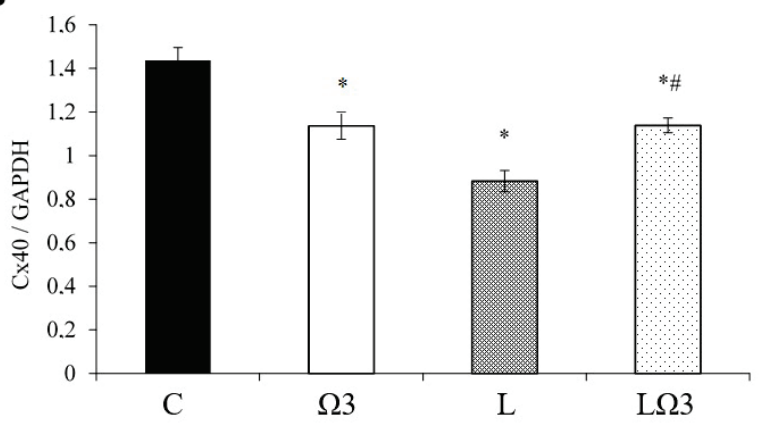

Fig. 7. A) Representative immunoblot of $\mathrm{C} x 40$ in hHTG rat aorta. B) Quantitative evaluation of total $\mathrm{C} \times 40$ expression normalized to protein GAPDH in the control rats $(C)$, the treated control $(\Omega 3)$, the inflammatory group $(\mathrm{L})$ and the treated inflammatory group $(L \Omega 3)$. Results are expressed as mean $\pm S E M, n=6$ animals per group, * $p<0.05$ vs. C, \# $p<0.05$ vs. L.

\section{Western blot analysis of Cx40 and CD68}

$\mathrm{Cx} 40$ expression measured in the aortic tissue corresponded with the morphometric evaluation. LPS application resulted in down-regulation of $\mathrm{Cx} 40$ expression in the L group when compared to the $\mathrm{C}$ group (Fig. 7). $\Omega 3$ FA treatment of the rats in the $L \Omega 3$ group resulted in up-regulation of $\mathrm{Cx} 40$ expression compared to the $\mathrm{L}$ one, but the levels of $\mathrm{Cx} 40$ protein remained significantly lower than in the $\mathrm{C}$ group. In the $\Omega 3$ group, $\mathrm{Cx} 40$ expression was lower than in the $\mathrm{C}$ one.

Western blot revealed significant increase of CD68 expression in the L group (Fig. 8). $\Omega 3$ FA treatment did not affect CD68 expression in the $\mathrm{L} \Omega 3$ group compared to the L group. $\Omega 3$ FA did not change CD68 expression in the $\Omega 3$ when compared to the $\mathrm{C}$ group.

A $\mathrm{CD} 68$

GAPDH
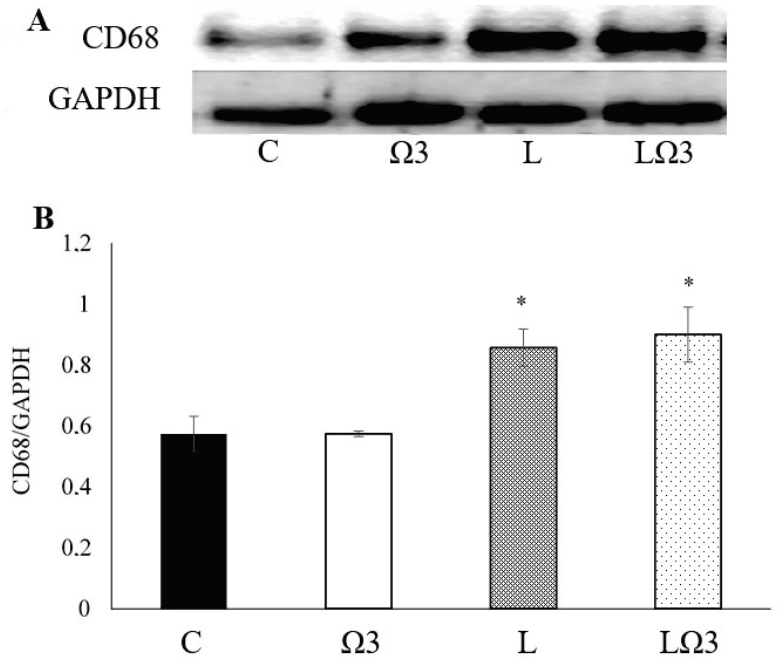

Fig. 8. A) Representative Western blot of CD68 in hHTG rat aorta. B) Quantitative evaluation of CD68 macrophage receptor expression normalized to protein GAPDH. C - control hHTG rats, $\Omega 3-$ hHTG rats treated with $\Omega 3 F A, L-$ hHTG rats injected with LPS, $L \Omega 3$ - hHTG rats injected with LPS and treated with $\Omega 3 F A$. Results are expressed as mean \pm SEM. $* p<0.05$ vs. C. 


\section{Discussion}

In the present work we demonstrated that 10-day $\Omega 3 F A$ supplementation suppressed LPS-induced abnormalities in the aorta of hHTG rats: it improved Cx40 expression associated with endothelium-dependent relaxation of the aorta.

We used the same experimental model as in our other study, in which LPS was applied to healthy Wistar rats (Frimmel et al. 2014). The used dose of LPS was lower than the dose inducing sepsis and death (Berczi et al. 1966, Thomas et al. 2014) and did not cause any mortality of the experimental animals.

LPS did not affect measured physiological parameters (blood pressure, heart rate and heart weight), but it caused reduction of body weight gain (Table 1). The changes are in accordance with data of Valles et al. (2000) who demonstrated that also a single exposure of rats to stressors, including LPS, can cause marked and lasting changes in foot intake in different ways.

LPS injected to hHTG rats increased TG levels when compared to the control hHTG rats that correspond with data of other studies (Feingold et al. 2009). Our results thus support that LPS is an additional risk factor for individuals with HTG. On the other hand, TG and chylomicrons were reported to neutralize the toxic effects of LPS in circulation and significantly improved survival of endotoxemic rats even after lethal LPS dose (Harris et al. 1993, Read et al. 1995). This ability of TG and chylomicrons might at least partially explain our result concerning no changes of plasma CRP levels observed after LPS application. Oxidative stress represents one of main factors contributing to damage of endothelial function. In order to verify the contribution of oxidative stress in the effects of LPS, we measured levels of MDA. Its enhanced concentration indicates increased lipid peroxidation and oxidative stress which could change endothelial function.

In our experiments, LPS induced impairment of endothelium-dependent relaxation of the aorta, but not endothelium-independent relaxation. Therefore, we suppose that the detrimental effect of LPS is targeted predominantly at the endothelium, in which signaling and metabolic disturbances can contribute to impaired endothelium-mediated vasodilation of the aorta. Increased activity of NOS, found in our experiments, could be a manifestation of endothelial dysfunction as well as macrophage-stimulated iNOS which produces NO involved in damaging endothelium. Moreover, enhanced
NAGA activity and increased values of LDH also point to cell injury including endothelial ones. Above mentioned actual changes of metabolism and inflammation in the LPS treated group can affect different mechanisms modulating endothelial function, including expression of Cx40 protein (Zhao et al. 2007, Alonso et al. 2010, Radosinska et al. 2011, Frimmel et al. 2014, Le Gal et al. 2015).

Cx-channels, including $\mathrm{Cx} 40$-ones, represent one of the key pathways for normal function of blood vessel wall. They allow spread of electrotonic signaling between cells of vascular wall modulating its vasomotion (De Wit and Griffith 2010). Therefore, LPS-induced decrease in expression of $\mathrm{Cx} 40$ isoform in the aorta could contribute to disturbances of endothelial cells homeostasis and thus impaired vascular tone of aorta. Cx40 has been suggested to be involved in vasodilation through the NO system (Alonso et al. 2010, Le Gal et al. 2015) and endothelium-derived hyperpolarizing factors (EDHF) (Looft-Wilson et al. 2012). Concerning the aorta, various pathophysiological conditions, including HTG, atherosclerosis and hypertension impaired its NO-dependent relaxation, while EDHF-mediated vasodilation, in contrast to smaller arteries, was not changed (Csanyi et al. 2007, De Wit and Wolfle 2007, Bartus et al. 2008). Moreover, EDHF signaling may also depend on density of myoendothelial junctions. Concerning the aorta, it was demonstrated that it contained less the junctions than smaller arteries (Shaun et al. 2009). In our experiments, LPS-related decrease in $\mathrm{Cx} 40$ expression in the aorta of hHTG rats was associated with impaired endothelium-dependent relaxation of the aorta and disturbances of its NO system, whereas endothelium-independent relaxation was unchanged. We did not examine mechanisms involved in EDHF signaling. However, based on all the above mentioned data, we suppose that LPS-induced changes of $\mathrm{Cx} 40$ expression in the aorta during HTG might be associated rather with NO-system than EDHF-mediated vasodilation. This remains to be determined in more detail.

Endothelial integrity and permeability depends on mutual interactions of intercellular gap and tight junctions (Nafasawa et al. 2006). In correlation, LPS resulted in different expression of $\mathrm{Cx} 40$ and occludin in Wistar rat aorta, which were accompanied with subcellular damage of intercellular junctions (Frimmel et al. 2014, Krizak et al. 2016). Local ultrastructural alterations of intercellular junctions were also seen in 
endothelium of hHTG rat aorta (Dlugošová et al. 2009b), indicating changes in cell-cell junctions. Therefore, we hypothesize that $\mathrm{Cx} 40$ expression in the rats injected with LPS might be at least partially modulated with disturbances of tight junctions, too.

Both, HTG and LPS represent independent risk factors for atherosclerosis and their effects on $\mathrm{Cx} 40$ expression can be diverse. In atherosclerotic arteries, reduced $\mathrm{Cx} 40$ expression was found in mice (Kwak et al. 2002, Chadjichrostos et al. 2010), while it was increased in rabbit (Wang et al. 2005). Other studies demonstrated LPS-induced Cx40 down-regulation in mouse aorta (Simon et al. 2004, Rignault et al. 2007) but up-regulation of $\mathrm{Cx} 40$ expression in rat aorta (Rignault et al. 2005, Frimmel et al. 2014). Our previous study showed that HTG increased Cx40 expression when compared to healthy Wistar rats (Okruhlicová et al. 2012). Here, we observed LPS-induced decrease of $\mathrm{Cx} 40$ expression in the aorta of hHTG rats.

The results thus indicate that $\mathrm{Cx} 40$ expression may vary according to the experimental models, type of vessel, animal species, and genetic predisposition as well as various pathophysiological conditions. LPS-induced downregulation of $\mathrm{Cx} 40$ expression suggests functional and structural remodeling of endothelial $\mathrm{Cx} 40-\mathrm{GJ}$ clusters in respect to actual metabolic and inflammatory conditions induced with LPS. Precise mechanisms, affecting $\mathrm{Cx} 40$ expression remain to be elucidated.

HTG is known to be associated with endothelial dysfunction (Bae et al. 2001, Cebova et al. 2006), which predispose endothelial cells to be more sensitive to various exogenous factors, including inflammatory factors as well as substances with protective effects.

Chronic dietary $\Omega 3 F$ F intake is well-known to suppress progression of vascular wall diseases and is strongly recommended in the management of HTG. $\Omega 3 F A$ possess multifactorial effects including antilipidemic and anti-inflammatory ones ( $\mathrm{Lu}$ et al. 2014, Tousoulis et al. 2014). In our experiment, the LPS challenged rats were treated with $\Omega 3 F A$ diet for 10 days to examine its short-term effects. The diet had no protective effect on TG and HDL concentration, therefore we suppose that 10 -day $\Omega 3 \mathrm{FA}$ administration is too short to influence lipid metabolic processes in hHTG rats injected with LPS. Surprisingly, $\Omega 3 F A$ diet caused increase in TG levels in the $\Omega 3$ group as well. Currently, there is no sufficient explanation of this result, but we hypothesize that it might be attributed to short-term diet rich in fats. Beneficial effects of regular consumption of
S3FA on TG levels have been observed approximately 40-60 days later.

Surprisingly, $\Omega 3 \mathrm{FA}$ diet caused elevation of triglyceride levels in the hHTG rats. It might mean that the diet, at this phase of experiment, does not have beneficial effects for hHTG rats. We are not able to explain the results at the present, but we hypothesize that it might be attributed to short-term diet rich in fats during actual metabolic conditions.

Although $\Omega 3 \mathrm{FA}$ diet had no anti-lipidemic effects in our experiment, it significantly decreased values of MDA and NAGA and ameliorated endothelium-dependent relaxation of the aorta. The results point to suppression of oxidative stress- and inflammation-related cellular damage. Nevertheless, the NOS activity in the L $\Omega 3$ group was even higher than in the LPS rats. It indicates the presence of eNOS activity and/or increased availability of NO probably due to high response of endothelial cells to anti-inflammatory and anti-oxidative effects of $\Omega 3 \mathrm{FA}$. Although $\Omega 3 \mathrm{FA}$ protected endothelial function, they did not reduce CD68 expression in the LPS rats. Elevated CD68 expression and TG levels might contribute to LPS-induced storage of TG in macrophages (Feingold et al. 1992), which however, in our case, had no deleterious effects on aorta relaxation.

S3FA-induced protection of endotheliumdependent aortic relaxation in the $L \Omega 3$ group was associated with significant increase of $\mathrm{Cx} 40$ protein expression. Because $\Omega 3 \mathrm{FA}$ suppressed values of oxidative stress, affected NO system, whereas did not affect lipid metabolism disorder, we hypothesize that normalization of $\mathrm{Cx} 40$ expression can be attributed mainly to $\Omega 3 \mathrm{FA}$ anti-oxidative and anti-inflammatory potencies. Due to already mentioned Cx40-eNOS interaction (Alonso et al. 2010, Le Gal et al. 2015), it is also possible to speculate that restoration of $\mathrm{Cx} 40$ by $\Omega 3 F A$ diet in LPS affected animals could improve eNOS activity. The results indicate that $\mathrm{Cx} 40$ expression can be involved in $\Omega 3$ FA-related amelioration of aortic relaxation function. The data are in concordance with our previous studies demonstrating protective effects of $\Omega 3 F A$ on LPS-induced changes in $\mathrm{Cx} 40$ expression in aorta of Wistar rats (Frimmel et al. 2014) and hHTGinduced disturbances in $\mathrm{Cx} 43$ expression in rat aorta (Dlugošová et al. 2009b). The modulation of $\mathrm{Cx} 40$ expression by $\Omega 3 \mathrm{FA}$ was also observed by Sarrazin et al. (2007) in canine atrial tissue.

Connexins are transmembrane proteins which 
very dynamically respond to actual conditions. $\Omega 3$ FA are an integral part of cellular membrane, therefore they can influence structure of membrane, determine its susceptibility to oxidative conditions and repair membrane transport properties (Rustan and Drevon 2005) including CX-channels. Biological effects of $\Omega 3 F A$ diet can also occur via peroxisome proliferator-activated receptors pathway which is involved in lipid metabolism (Lu et al. 2014). However, the mechanisms by which $\Omega 3$ FA protect endothelial Cx40 expression in the aorta of the hHTG rats after LPS administration, remain still in discussion.

\section{Conclusions}

Our results indicate involvement of $\mathrm{Cx} 40$ expression in LPS-induced endothelial damage of the aorta in rats with inherited hypertriglyceridemia. The findings also suggest that hHTG rats suffering from LPS-induced injury might benefit from 10-day $\Omega 3 \mathrm{FA}$ therapy because of the protection of endothelial function due to increased $\mathrm{Cx} 40$ expression. In this respect, our results suggest that also short-term $\Omega 3 \mathrm{FA}$ diet may be of great importance in some pathology.

\section{Conflict of Interest}

There is no conflict of interest.

\section{Acknowledgements}

This work was supported by VEGA grant no. 2/0065/13 and 2/0022/16.

\section{References}

AL-BANNAWI A, AL-WESEBAI K, TAHA S, BAKHIET M: Chlamydia pneumoniae induces chemokine expression by platelets in patients with atherosclerosis. Med Princ Pract 20: 438-443, 2011.

ALONSO F, BOITTIN FX, BÉNY JL, HAEFLIGER JA: Loss of connexin40 is associated with decreased endothelium-dependent relaxations and eNOS levels in the mouse aorta. Am J Physiol 299: H1365-H1373, 2010.

BACOVA B, RADOSINSKA J, KNEZL V, KOLENOVA L, WEISMANN P, NAVAROVA J, BARANCIK M, MITASIKOVA M, TRIBULOVA N: Omega-3 fatty acids and atorvastatin suppress ventricular fibrillation inducibility in hypertriglyceridemic rat hearts: implication of intercellular coupling protein, connexin- 43 . J Physiol Pharmacol 61: 717-723, 2010.

BAE JH, BASSENGE E, KIM KB, KIM YN, KIM KS, LEE HJ, MOON KC, LEE MS, PARK KY, SCHWEMMER M: Postprandial hypertriglyceridemia impairs endothelial function by endhanced oxidant stress. Atheroslerosis 155: 517-523, 2001.

BARTUS M, LOMNICKA M, KOSTOGRYS RB, KAZMIERCZAK P, WATALA C, SLOMINSKA EM, SMOLENSKI RT, PISULEWSKI PM, ADAMUS J, GEBICKI J, CHLOPICKI S: 1-Methylnicotinamide (MNA) prevents endothelial dysfunction in hypertriyglyceridemic and diabetic rats. Pharmacol Rep 60 : 127-138, 2008.

BERCZI I, BERTÓK L, BEREZNAI T: Comparative studies on the toxicity of Escherichia coli lipopolysaccharide endotoxin in various animal species. Can J Microbiol 12: 1070-1071, 1966.

BERNATOVA I, PECHÁŇOVÁ O, BABÁL P, KYSELÁ S, ŠTVRTINA S, ANDRIANTSITOHAINA R: Wine polyphenols improve cardiovascular remodeling and vascular function in NO-deficient hypertension. $A m J$ Physiol 282: 942-948, 2002.

BRADFORD MM: A rapid and sensitive method for the quantitation of microgram quantities of protein utilizing the principle of protein-dye binding. Anal Biochem 72: 248-254, 1976.

BRISSET AC, ISAKSON BE, KWAK BR: Connexins in vascular physiology and pathology. Antioxid Redox Signal 11: 267-282, 2009.

BURNIER L, FONTANA P, ANGELILLO-SCHERRER A, KWAK BR: Intercellular communication in atherosclerosis. Physiology 24: 36-44, 2009.

CALDER PC: The role of marine omega-3 (n-3) fatty acids in inflammatory processes, atherosclerosis and plaque stability. Mol Nutr Food Res 56: 1073-1080, 2012.

CEBOVA M, KRISTEK F, KUNES J: Differential remodeling of carotid artery in spontaneously hypertensive and hereditary hypertriglyceridemic rats. Physiol Res 55 (Suppl 1): S81-S87, 2006. 
CHADJICHRISTOS CE, SCHECKENBACH KE, VAN VEEN TA, RICHANI SARIEDDINE MZ, DE WIT C, YANG Z, ROTH I, BACCHETTA M, VISWAMBJARAN H, FOGLIA B, DUDEZ T, VAN KEMPEN MJ, COENNIAERTS FE, MIQUEROL L, DEUTSCH U, JONGSMA HJ, CHANSON M, KWAK BR: Endothelial-specific deletion of connexin40 promotes atherosclerosis by increasing CD73-dependent leukocyte adhesion. Circulation 121: 123-131, 2010.

CSANYI G, LEPRAN I, FLESCH T, TELEGDY G, SZABO G, MEZEI Z: Lack of endothelium-derived hyperpolarizing factor (EDHG) up-regulation in endothelial dysfunction in aorta in diabetic rats. Pharmacol Rep 59: 447-455, 2007.

DE WIT C, GRIFFITH TM: Connexins and gap junctions in the EDHF phenomenon and conducted vasomotor responses. Pflugers Arch - Eur J Physiol 459: 897-914, 2010.

DE WIT C, WOLFLE SE: EDHF and gap junctions: important regulators of vascular tone within the microcirculation. Curr Pharm Biotechnol 8: 11-25, 2007.

DLUGOSOVA K, OKRUHLICOVA L, MITASIKOVA M, SOTNIKOVA R, BERNATOVA I, WEISMANN P, SLEZAK J, TRIBULOVA N: Modulation of connexin-43 by omega-3 fatty acids in the aorta of old spontaneously hypertensive rats. J Physiol Pharmacol 60: 63-69, 2009a.

DLUGOŠOVÁ K, WEISMANN P, BERNATOVA I, SOTNIKOVA R, SLEZAK J, OKRUHLICOV L: Omega-3 fatty acids and atorvastatin affect connexin 43 expression in the aorta of hereditary hypertriglyceridemic rats. Can $J$ Physiol Pharmacol 87: 1074-1082, 2009b.

DRAPER HH, HADLEY M: Malondialdehyde determination as index of lipid peroxidation. Methods Enzymol 186: 421-431, 1989.

FEINGOLD KR, STAPRANS I, MEMON RA, MOSER AH, SHIGENAGA JK, SOERRLER W, DINARELLO CA, GRUNFELD C: Endotoxin rapidly induces changes in lipid metabolism that produce hypertriglyceridemia: low doses stimulate hepatic triglyceride production while high doses inhibit clearance. J Lipid Res 33: 1765$1776,1992$.

FIGUEROA XF, DULING BR: Gap junctions in the control of vascular function. Antioxid Redox Signal 11: 251-266, 2009.

FRIMMEL K, VLKOVICOVA J, SOTNIKOVA R, NAVAROVA J, BERNATOVA I, OKRUHLICOVA L: The effect of omega-3 fatty acids on expression of connexin-40 in wistar rat aorta after lipopolysaccharide administration. J Physiol Pharmacol 65: 83-94, 2014.

GUZIK T, KORBUT R, ADAMEK-GUZIK T: Nitric oxide and superoxide in inflammation. $J$ Physiol Pharmacol 54: 469-487, 2003.

HARRIS HW, GRUNFELD C, FEINGOLD KR, READ TE, KANE JP, JONES AL, EICHBAUM EB, BLAND GF, RAPP JH: Chylomicrons alter the fate of endotoxin, decreasing tumor necrosis factor release and preventing death. J Clin Invest 91: 1028-1034, 1993.

KRAMER JH, MURTHI SB, WISE RM, MAK IT, WEGLICKI WB: Antioxidant and lysosomotropic properties of acute D-propranolol underlies its cardioprotection of postischemic hearts from moderate iron-overloaded rats. Exp Biol Med 231: 473-484, 2006.

KRIZAK J, FRIMMEL K, BERNATOVA I, NAVAROVA J, SOTNIKOVA R, OKRUHLICOVA L: The effect of $\Omega$-3 polyunsaturated fatty acids on endothelial tight junction occludin expression in rat aorta during lipopolysaccharide-induced inflammation. Iran J Basic Med Sci 19: 290-299, 2016.

KWAK BR, MULHAUPT F, VEILLARD N, GROS DB, MACH F: Altered pattern of vascular connexin expression in atherosclerotic plaques. Arterioscler Thromb Vasc Biol 22: 225-230, 2002.

LAIRD DW: The gap junction proteome and its relationship to disease. Trends Cell Biol 20: 92-101, 2010.

LE GAL L, ALONSO F, MAZZOLAI L, MEDA P, HAEFLIGER JA: Interplay between connexin40 and nitric oxide signaling during hypertension. Hypertension 65: 910-915, 2015.

LIBBY P, SIMON DI: Inflammation and thrombosis: the clot thickens. Circulation 103: 1718-1720, 2001.

LOOFT-WILSON RC, BILLAUD M, JOHNSTONE SR, STRAUB AC, ISAKSON BE: Interaction between nitric oxide signaling and gap junctions: effects on vascular function. Biochim Biophys Acta 1818: 1895-1902, 2012.

LU M, KHO R, MUNFORD RS: Prolonged triglyceride storage in macrophages: $\mathrm{pH}_{0}$ trumps $\mathrm{pO}_{2}$ and TLR4. J Immunol 193: 1392-1397, 2014. 
MÉZEŠOVÁ L, JENDRUCHOVÁ-JAVORKOVÁ V, VLKOVIČOVÁ J, OKRUHLICOVÁ L, FRIMMEL K, NAVAROVA J, KYSELOVA-BRNOLIAKOVA Z, VRBJAR N: Supplementation with n-3 polyunsaturated fatty acids to lipopolysaccharide-induced rats improved inflammation and functional properties of renal Na, K-ATPase. Nutr Res 33: 772-779, 2013.

NAGASAWA K, CHIBA H, FUJITA H, KOJIMA T, SAITO T, ENDO T, SAWADA N: Possible involvement of gap junctions in the barrier function of tight junctions of brain and lung endothelial cells. $J$ Cell Physiol 208: 123-132, 2006.

NAVAROVA J, NOSÁLOVÁ V: Effect of H2-receptor antagonists on indomethacin-induced lysosomal enzyme release from rat gastric mucosa. Methods Find Exp Clin Pharmacol 16: 119-124, 1994.

OKRUHLICOVÁ L', FRIMMEL K, WEISMANN P, SLEZÁK J: The effect of hypertriglyceridemia on the integrity of endothelial monolayer structure of rat aorta: electron microscopic and immunofluorescent analysis. In: Current Microscopy Contributions to Advances in Science and Technology. A MÉNDEZ-VILAS (ed), Formatex, 2012, pp 295-301.

OKUMURA K, IMAMURA A, MURAKAMI R, NUMAGUCHI Y, MATSUI H, TOYOAKI M: Endothelial function and early atherosclerotic changes. Future Cardiol 1: 501-508, 2005.

OVIEDO-ORTA E, ERRINGTON RJ, EVANS WH: Gap junction intercellular communication during lymphocyte transendothelial migration. Cell Biol Intern 26: 253-263, 2002.

PEPPES V, RAMMOS G, MANIOS E, KOROBOKI E, ROKAS S, ZAKOPOULOS N: Correlation between myocardial enzyme serum levels and markers of inflammation with severity of coronary artery disease and Gensini score: a hospital-based, prospective study in Greek patients. Clin Interv Aging 3: 699-710, 2008.

PERKINS GA, GOODENOUGH DA, SOSINSKY GE: Formation of the gap junction intercellular channel requires a 30 rotation for interdigitating two opposing connexons. J Mol Biol 277: 171-177, 1998.

PIRILLO A, CATAPANO AL: Omega-3 polyunsaturated fatty acids in the treatment of atherogenic dyslipidemia. Atheroscler Suppl 14: 237-242, 2013.

RADOSINSKA J, BACOVA B, BERNATOVA I, NAVAROVA J, ZHUKOVSKA A, SHYS A, OKRUHLICOVA L, TRIBULOVA N: Myocardial NOS activity and connexin-43 expression in untreated and omega-3 fatty acids-treated spontaneously hypertensive and hereditary hypertriglyceridemic rats. Mol Cell Biochem 347: 163-173, 2011.

READ TE, GRUNFELD C, KUMWENDA Z, CALHOUN MC, KANE JP, FEINGOLD KR, RAPP JH: Triglyceriderich lipoproteins improve survival when given after endotoxin in rats. Surgery 117: 62-67, 1995.

RIGNAULT S, HAEFLIGER JA, GASSER D, MARKERT M, NICOD P, LIAUDET L, WAEBER B, FEIHL F: Sepsis up-regulates the expression of connexin 40 in rat aortic endothelium. Crit Care Med 33: 1302-1310, 2005.

RIGNAULT S, HAEFLIGER JA, WAEBER B, LIAUDET L, FEIHL F: Acute inflammation decreases the expression of connexin 40 in mouse lung. Shock 28: 78-85, 2007.

RUSTAN AC, DREVON CA: Fatty acids: structures and properties. eLS, John Wiley \& Sons Ltd., Chichester, http://www.els.net; doi: 10.1038/npg.els.0003894, 2005.

SARRAZIN JF, COMEAU G, DALEAU P, KINGMA J, PLANTE I, FOURNIER D, MOLIN F: Reduced incidence of vagally induced atrial fibrillation and expression levels of connexins by $\mathrm{n}-3$ polyunsaturated fatty acids in dogs. J Am Coll Cardiol 50: 1505-1512, 2007.

SHAUN LS, GZIK JD, LEE RMKW: Arterial internal elastic lamina holes: relationship to function? $J$ Anat 214: 258-266, 2009.

SIMON AM, MCWHORTER AR, CHEN H, JACKSON CL, OUELLETTE Y: Decreased intercellular communication and connexin expression in mouse aortic endothelium during lipopolysaccharide-induced inflammation. $J$ Vasc Res 41: 323-333, 2004.

SOTNIKOVA R, SKALSKA S, OKRUHLICOVA L, NAVAROVA J, KYSELOVA Z, ZUROVA J, STEFEK M, HOZOVA R, NOSALOVA V: Changes in the function and ultrastructure of vessels in the rat model of multiple low dose streptozotocin-induced diabetes. Gen Physiol Biophys 25: 289-302, 2006.

SÖHL G, WILLECKE K: Gap junctions and the connexin protein family. Cardiovasc Res 62: 228-232, 2004. 
SPRAGUE AH, KHALIL RA: Inflammatory cytokines in vascular dysfunction and vascular disease. Biochem Pharmacol 78: 539-552, 2009.

THOMAS RC, BATH MF, STOVER CM, LAMBERT DG, THOMPSON JP: Exploring LPS-induced sepsis in rats and mice as a model to study potential protective effects of the nociceptin/orphanin FQ system. Peptides 61: 56-60, 2014.

TOUSOULIS D, PLASTIRAS A, SIASOS G, OIKONOMOU E, VERVENIOTIS A, KOKKOU E, MANIATIS K, GOUPIPOULOS N, MILIOU A, PARASKEVOPOULOS T, STEFANADIS C: Omega-3 PUFAs improved endothelial function and arterial stiffnes with a parallel antiinflammattory effect in adults with metabolic syndrome. Atheroslcerosis 32: 10-16, 2014.

UCHIUMI D, KOBAYASHI M, TACHIKAWA T, HASEQAWA K: Subcutaneous and continuous administration of lipopolysaccharide increases serum levels of triglyceride and monocyte chemoattractant protein-1 in rats. J Periodontal Res 39: 120-128, 2004.

VALLÉS A, MARTÍ O, GARCÍA A, ARMARIO A: Single exposure to stressors causes long-lasting, stress-dependent reduction of food intake in rats. Am J Physiol Regul Integr Comp Physiol 279: R1138-R1144, 2000.

VAN KEMPEN MJA, JONGSMA HJ: Distribution of connexin37, connexin40 and connexin43 in the aorta and coronary artery of several mammals. Histochem Cell Biol 112: 479-486, 1999.

VRANA A, KAZDOVA L: The hereditary hypertriglyceridemic nonobese rat: an experimental model of human hypertriglyceridemia. Transplant Proc 22: 2579, 1990.

WANG LH, CHEN JZ, SUN YL, ZHANG FR, ZHU JH, HU SJ, WANG DH: Statins reduce connexin40 and connexin43 expression in atherosclerotic aorta of rabbits. Int J Cardiol 100: 467-475, 2005.

WONG CW, CHRISTEN T, KWAK BR: Connexins in leukocytes: shuttling messages? Cardiovasc Res 62: 357-367, 2004.

ZHAO W, DIZ DI, ROBBINS ME: Oxidative damage pathways in relation to normal tissue injury. Brit $J$ Radiol 7: 145-152, 2007.

ZICHA J, PECHÁNOVÁ O, CACÁNYIOVÁ S, CEBOVÁ M, KRISTEK F, TOROK J, SIMKO F, DOBESOVA Z, KUNES J: Hereditary hypertriglyceridemic rat: a suitable model of cardiovascular disease and metabolic syndrome? Physiol Res 55 (Suppl 1): S49-S63, 2006. 